\title{
4,4'-Diaponeurosporene from Lactobacillus plantarum subsp. plantarum KCCP11226: Low Temperature Stress- Induced Production Enhancement and In Vitro Antioxidant Activity
}

\author{
Mibang Kim ${ }^{1 \dagger}$, Dong-Hyun Jung ${ }^{2 \dagger}$, Dong-Ho Seo ${ }^{3,4}$, Young-Seo Park ${ }^{5}$, and Myung-Ji Seo ${ }^{1,6,7 *}$ \\ 'Department of Bioengineering and Nano-Bioengineering, Graduate School of Incheon National University, \\ Incheon 22012, Republic of Korea \\ ${ }^{2}$ Bacteria Research Team, Nakdonggang National Institute of Biological Resources, Sangju 37242, Republic of Korea \\ ${ }^{3}$ Department of Food Science and Technology, College of Agriculture and Life Sciences, Jeonbuk National \\ University, Jeonju 54896, Republic of Korea \\ ${ }^{4}$ Department of Agricultural Convergence Technology, Jeonbuk National University, Jeonju 54896, Republic of Korea \\ ${ }^{5}$ Department of Food Science and Biotechnology, Gachon University, Seongnam 13120, Republic of Korea \\ ${ }^{6}$ Division of Bioengineering, Incheon National University, Incheon 22012, Republic of Korea \\ ${ }^{7}$ Institute for New Drug Development, Incheon National University, Incheon 22012, Republic of Korea
}

Received: October 12, 2020 Accepted: November 2, 2020

First published online: November 4, 2020

*Corresponding author Phone: +82-32-835-8267 Fax: +82-32-835-0804 E-mail: mjseo@inu.ac.kr

${ }^{\dagger}$ Mibang Kim and Dong-Hyun Jung contributed equally to this work.

Supplementary data for this paper are available on-line only at http://jmb.or.kr.

pISSN 1017-7825 eISSN 1738-8872

Copyright(C) 2021 by The Korean Society for Microbiology and Biotechnology
Carotenoids, which have biologically beneficial effects and occur naturally in microorganisms and plants, are pigments widely applied in the food, cosmetics and pharmaceutical industries. The compound 4,4'-diaponeurosporene is a $C_{30}$ carotenoid produced by some Lactobacillus species, and Lactobacillus plantarum is the main species producing it. In this study, the antioxidant activity of 4,4'-diaponeurosporene extracted from $L$. plantarum subsp. plantarum KCCP11226 was examined. Maximum carotenoid content $\left(0.74 \pm 0.2\right.$ at $\left.A_{470}\right)$ was obtained at a relatively low temperature $\left(20^{\circ} \mathrm{C}\right)$. The DPPH radical scavenging ability of 4,4'-diaponeurosporene (1 $\mathrm{mM}$ ) was approximately 1.7-fold higher than that of butylated hydroxytoluene (BHT), a well-known antioxidant food additive. In addition, the ABTS radical scavenging ability was shown to be 2.3- to 7.5-fold higher than that of BHT at the range of concentration from $0.25 \mathrm{mM}$ to $1 \mathrm{mM}$. The FRAP analysis confirmed that 4,4'diaponeurosporene $(0.25 \mathrm{mM})$ was able to reduce $\mathrm{Fe}^{3+}$ by 8.0 -fold higher than that of BHT. Meanwhile, 4,4'-diaponeurosporene has been confirmed to be highly resistant to various external stresses (acid/bile, high temperature, and lysozyme conditions). In conclusion, L. plantarum subsp. plantarum KCCP11226, which produces 4,4'-diaponeurosporene as a functional antioxidant, may be a potentially useful strain for the development of functional probiotic industries.

Keywords: Lactobacillus plantarum subsp. plantarum, 4,4'-diaponeurosporene, $\mathrm{C}_{30}$ carotenoid, antioxidant, low temperature

\section{Introduction}

Carotenoids, natural pigments belonging to the isoprenoid group, exhibit yellow, orange, red, and purple colors and naturally occur in algae, yeasts, fungi, bacteria, and plants $[1,2]$. Carotenoids have various functions that are beneficial to human health; hence, they have been widely applied in the food, cosmetic, and pharmaceutical industries [1,2]. Representatively, they have antioxidant, anticancer, and antimicrobial activity, as well as immune regulatory functions [2].

Recently, scientific interest related to carotenoid production using microorganisms has been increasing. Microbial pigments are a better alternative to synthetic or plant pigments because of their safety, availability, nonseasonality, scalability, high yield, and reduced process [2]. Most carotenoids found in bacteria consist of eight isoprene units with a 40-carbon structure (tetraterpenoids, $C_{40}$ carotenoids) such as astaxanthin, lycopene, and $\beta$ carotene. However, triterpenoids $\left(\mathrm{C}_{30}\right.$ carotenoids) have been reported to be found only in several bacterial species, such as Lactobacillus plantarum, Enterococcus faecium, Staphylococcus aureus, Methylobacterium rhodinum, and some heliobacteria [3]. 
L. plantarum is a widespread member of the genus of Lactobacillus, commonly found in ecological niches such as various dairy products, vegetables, fish and gastrointestinal tracts [4]. It has been extensively used as a probiotic strain to provide various beneficial effects on human health [5]. Recently, several biotechnological studies have reported on $L$. plantarum, which can produce the $\mathrm{C}_{30}$ carotenoid 4,4'-diaponeurosporene. In general, bacterial carotenoids can be produced from farnesyl pyrophosphate (FPP), a product of the mevalonate pathway [6]. Garrido-Fernández et al. (2010) reported that 4,4'-diaponeurosporene can be synthesized through a series of FPP desaturation steps by dehydrosqualene synthase ( $c r t M)$ and dehydrosqualene desaturase ( $c r t N)$ in L. plantarum [3]. In addition, Turpin et al. (2016) suggested that the identification of $\operatorname{crtM}-\operatorname{crt} N$ genes, accompanied by biochemical analysis, is an efficient method for screening $\mathrm{C}_{30}$ carotenoid-producing lactic acid bacteria [7]. Our previous studies reported that L. plantarum subsp. plantarum KCCP11226 isolated from kimchi, a Korean fermented vegetable, induced 4,4'-diaponeurosporene production under various stress environments by upregulating the carotenoid biosynthetic operon $\operatorname{crt} M-\operatorname{crtN}[8,9]$. Furthermore, they showed that the $\operatorname{crt} M-\operatorname{crtN}$ operon can be detected in some Lactobacillus species, including L. paraplantarum, L. paracasei, L. herbarum, L. mundanjiangensis, and L. florum, but it is found in most L. plantarum species, and is well conserved [9].

One of the important properties of carotenoids is to act as antioxidants that can protect cells and tissues from reactive oxygen species (ROS) damage $[10,11]$. In general, the harmful effects of ROS on cells are most often cell death due to damage to cell structures, including lipids and membranes, proteins, and nucleic acids [12]. Indeed, most of the focus on carotenoids in recent years has been to understand their function, especially as antioxidants [13]. Recently, the resistance of $4,4^{\prime}$-diaponeurosporene to oxidative stress has been reported [8, 14]. This carotenoid is considered to act as an antioxidant by removing free radicals through conjugated double bonds [3, $15,16]$. As described above, $L$. plantarum, a main species of Lactobacillus that produces $4,4^{\prime}$-diaponeurosporene with the $\operatorname{crt} M-\operatorname{crtN}$ operon, is important. Although the antioxidant activities of various types of carotenoids have been studied, that of 4,4'-diaponeurosporene from $L$. plantarum is still unclear.

In this study, we evaluated the antioxidant activity of 4,4'-diaponeurosporene produced from L. plantarum subsp. plantarum KCCP11226 through several kinds of antioxidant measurements. In addition, the availability of strain KCCP11226 for probiotic use was investigated through in vitro experiments on safety and functionalities such as antibiotic resistance, cell surface hydrophobicity, and stress tolerance, including acid/bile, high temperature, and lysozyme. To the best of our knowledge, this study is the first report on the antioxidant activity of 4,4'-diaponeurosporene produced by Lactobacillus.

\section{Materials and Methods}

\section{Bacterial Strain and Reagents}

L. plantarum subsp. plantarum KCCP11226 was previously isolated from a Korean fermented food [8]. L. rhamnosus GG (KCTC 5033), which was used as reference strain in this study, was purchased from the Korean Collection for Type Cultures (KCTC, Korea). De Man Rogosa and Sharpe (MRS) broth was purchased from MBcell (Korea) and oxgall was obtained from Difco Laboratories (USA). Antibiotic agents including ampicillin, erythromycin, gentamicin, ciprofloxacin, lincomycin, novobiocin, tetracycline, and streptomycin were purchased from Sigma-Aldrich (USA). All other chemicals used in this study were of analytical grade and obtained from Sigma-Aldrich.

\section{Cell Surface Hydrophobicity}

Bacterial cell surface hydrophobicity was evaluated according to Ekmekci et al. (2009), with slight modifications [17]. Briefly, KCCP 11226 was cultivated at $30^{\circ} \mathrm{C}$ for $24 \mathrm{~h}$ and then harvested by centrifugation at $10,000 \times g$ for $10 \mathrm{~min}$, followed by washing twice with PBS ( $\mathrm{pH}$ 7.0). The pellet was resuspended in PBS buffer to an optical density (OD) of 0.6 . One milliliter of test hydrocarbons (xylene or toluene) was added to the cell suspension and mixed for $2 \mathrm{~min}$. The two phases were separated by incubation for $30 \mathrm{~min}$ at room temperature. Afterward, the aqueous phases were measured by absorbance at $600 \mathrm{~nm}$. The percentage of cell surface hydrophobicity was calculated using the following equation: Hydrophobicity $(\%)=\left[\left(A_{0}-A_{1}\right) / A_{0}\right] \times 100$, where $A_{0}$ and $A_{1}$ represent the absorbance at $600 \mathrm{~nm}$ before and after mixing, respectively.

\section{Antibiotic Resistance}

KCCP 11226 was cultivated at $30^{\circ} \mathrm{C}$ for $24 \mathrm{~h}(100 \mu \mathrm{l})$ and then spread on MRS agar medium, and antibiotic discs containing ampicillin $(100 \mu \mathrm{g} / \mathrm{ml})$, erythromycin $(25 \mu \mathrm{g} / \mathrm{ml})$, gentamicin $(30 \mu \mathrm{g} / \mathrm{ml})$, ciprofloxacin $(10 \mu \mathrm{g} / \mathrm{ml})$, lincomycin $(15 \mu \mathrm{g} / \mathrm{ml})$, novobiocin $(10 \mu \mathrm{g} / \mathrm{ml})$, tetracycline $(30 \mu \mathrm{g} / \mathrm{ml})$, and streptomycin $(50 \mu \mathrm{g} / \mathrm{ml})$ were placed on the inoculated plates. All plates were incubated at $30^{\circ} \mathrm{C}$ for $24 \mathrm{~h}$ and the inhibition zones were measured.

\section{Survival Under Environmental Stress}

Survival rates after exposure to stress were evaluated according to Hagi et al. (2013) [14]. KCCP11226 was cultured in MRS medium for $24 \mathrm{~h}$ at $30^{\circ} \mathrm{C}$, harvested by centrifugation at $8,000 \times g$ for $10 \mathrm{~min}$, and rinsed twice with saline. The rinsed bacterial pellets were resuspended in $500 \mu$ lof low-pH saline ( $\mathrm{pH} 1.5$ or 2.0, adjusted with $\mathrm{HCl})$, oxgall $(10 \%$ or $20 \%)$, or lysozyme $(8$ or $12 \mathrm{mg} / \mathrm{ml})$ to determine survival rate under each of the environmental stresses. Under each of these stress conditions, the bacterial suspension was exposed to $30^{\circ} \mathrm{C}$ for $90 \mathrm{~min}$ (acid and bile conditions) or $180 \mathrm{~min}$ (lysozyme conditions). After that, cells were harvested and washed twice with saline, followed by resuspension in saline $(500 \mu \mathrm{l})$. Meanwhile, to investigate heat tolerance, the rinsed bacterial pellets resuspended in $500 \mu \mathrm{l}$ of saline were exposed at $55^{\circ} \mathrm{C}$ or $60^{\circ} \mathrm{C}$ for $20 \mathrm{~min}$. The number of cell 
colonies before and after exposure to heat was counted by viable cells on MRS agar. The viable cells were counted and calculated using the following equation:

Survival rate $(\%)=($ Number of cells after exposure to conditions/initial number of cells $) \times 100$

\section{Temperature Stress-Induced Carotenoid Production}

To create a seed culture, strain KCCP11226 was statically incubated at $30^{\circ} \mathrm{C}$ for $18 \mathrm{~h}$ in MRS broth. Seed culture was inoculated ( $1 \%, \mathrm{v} / \mathrm{v})$ into MRS medium $(3 \mathrm{~L})$ in an Erlenmeyer flask $(5 \mathrm{~L})$ and the flask was statically incubated at $30^{\circ} \mathrm{C}$. Samples $(100 \mathrm{ml})$ were taken every $2 \mathrm{~h}$. Next, to study the effect of temperature on carotenoid production, additional cultures were incubated, changing only the temperature, under the same culture conditions. The bacterial cultures incubated at $10^{\circ} \mathrm{C}, 20^{\circ} \mathrm{C}, 30^{\circ} \mathrm{C}$, and $40^{\circ} \mathrm{C}$ were taken after $24 \mathrm{~h}$ incubation. The cell density $\left(\mathrm{OD}_{600}\right)$ and crude carotenoid $\left(\mathrm{A}_{470}\right)$ of the collected samples were measured.

\section{Extraction and Purification of Carotenoid}

The yellow pigments of strain KCCP11226 were extracted according to our previous study [9]. In brief, $100 \mathrm{ml}$ of cultured cells were harvested by centrifugation at $10,000 \times \mathrm{g}$ for $10 \mathrm{~min}$ and extracted in $5 \mathrm{ml}$ methanol overnight. Next, $5 \mathrm{ml}$ of hexane and $2.5 \mathrm{ml}$ of distilled water were added to the methanol extract. After centrifugation at $8,000 \times g$ for $10 \mathrm{~min}$, the organic phase containing carotenoids was transferred to a $15 \mathrm{ml}$ tube. The organic phase was evaporated and then dissolved in $1 \mathrm{ml}$ of petroleum ether. The pigmentation levels of crude carotenoids were measured at an absorption wavelength of $470 \mathrm{~nm}\left(\mathrm{~A}_{470}\right)$ using a spectrophotometer (Shimadzu, Japan).

For purification of 4,4'-diaponeurosporene, the isolated carotenoids were salted out with $5 \mathrm{~N} \mathrm{NaCl}$ solution and re-extracted with an equal volume of ethyl acetate (EtOAc). The upper phase was loaded onto an anhydrous sodium sulfate column (BioBasic, Canada) for dehydration and then evaporated. The dried carotenoids were dissolved in EtOAc, filtered, and purified by loading on a silica gel column [18]. The total amount of purified carotenoids was quantified using the previously reported extinction coefficient of 4,4'-diaponeurosporene [19, $20]$.

\section{Antioxidant Activity of 4,4'-Diaponeurosporene}

The scavenging activity of 2,2-diphenyl-1-picrylhydrazyl (DPPH) free radical was determined according to the method described by Kim et al. (2019) with slight modifications [8]. The 4,4'-diaponeurosporene was dissolved in DMSO at final concentrations of $0.25,0.5$, and $1 \mathrm{mM}$, and $100 \mu \mathrm{l}$ of each solution was added to equal volumes of ethanol containing $0.2 \mathrm{mM} \mathrm{DPPH}$. The mixture was left for $30 \mathrm{~min}$ at room temperature, and then the absorbance of the resulting solution was measured at $517 \mathrm{~nm}\left(\mathrm{~A}_{517}\right)$. The scavenging ability was expressed as follows: scavenging activity $(\%)=\left(1-\left[\mathrm{A}_{\text {sample }}-\mathrm{A}_{\text {blank }}\right] / \mathrm{A}_{\text {control }}\right) \times 100$. As a control, the same reactant that did not contain 4,4'-diaponeurosporene was used. Butylated hydroxytoluene (BHT) was also assayed as an antioxidant reference.

The 4,4'-diaponeurosporene was further characterized by the 2,2'-azino-bis(3-ethylbenzothiazoline-6sulfonic acid) (ABTS) cation radical assay with a slight modification of the method described by Yang et al. (2017) [21]. First, ABTS radical solution was generated after reaction of $7 \mathrm{mM}$ ABTS in $20 \mathrm{mM}$ sodium acetate buffer (pH $4.5)$ with an oxidant $\left(2.45 \mathrm{mM}\right.$ potassium persulfate) in the dark for $12-16 \mathrm{~h}$ at $4^{\circ} \mathrm{C}$ before use. The ABTS radical solution was diluted with $20 \mathrm{mM}$ sodium acetate buffer to an absorbance of $0.7 \pm 0.02$ at $734 \mathrm{~nm}$. After adding $100 \mu \mathrm{l}$ of $4,4^{\prime}$-diaponeurosporene dissolved in DMSO to an equal volume of ABTS radical solution, the absorbance was measured at $734 \mathrm{~nm}\left(\mathrm{~A}_{734}\right)$ after incubation for $10 \mathrm{~min}$ in the dark. The ABTS radical scavenging activity of 4,4'-diaponeurosporene was expressed as Trolox equivalent antioxidant capacity.

The ferric reducing antioxidant power (FRAP) of 4,4'-diaponeurosporene was estimated according to Han et al. (2017) [22]. Briefly, FRAP reagents were prepared by mixing acetate buffer (300 mM, pH 3.6), $10 \mathrm{mM}$ 2,4,6Tris(2-pyridyl)-s-triazine (TPTZ) solution in $40 \mathrm{mM} \mathrm{HCl}$, and $20 \mathrm{mM} \mathrm{FeCl}_{3} \cdot 6 \mathrm{H}_{2} \mathrm{O}$ at 10:1:1 (v/v/v). The FRAP reagent solution was maintained at $37^{\circ} \mathrm{C}$. Then, $100 \mu \mathrm{l}$ of $4,4^{\prime}$-diaponeurosporene was allowed to react with $3 \mathrm{ml}$ of FRAP reagent solution and $300 \mu \mathrm{l}$ of ultrapure water for $5 \mathrm{~min}$ at room temperature in the dark. The absorbance values of the mixture were measured at $593 \mathrm{~nm}\left(\mathrm{~A}_{593}\right)$. The FRAP values were expressed as $\mathrm{FeSO}_{4}(\mathrm{mM})$ equivalents using the $\mathrm{FeSO}_{4} \cdot 7 \mathrm{H}_{2} \mathrm{O}$ standard curve.

\section{Statistical Analysis}

The results of the experiments were expressed as means \pm standard deviations of three independent measurements. The significance of differences in means was evaluated using analysis of variance (ANOVA) with Tukey-Kramer multiple comparison tests, unless mentioned otherwise. The FRAP data was analyzed using an unpaired $t$-test with Welch's correction. Differences with $p$ values of less than 0.01 were considered significant.

\section{Results and Discussion}

\section{Probiotic Properties of $L$. plantarum subsp. plantarum KCCP11226}

To produce effective probiotic strains, the safety and functionalities such as antibiotic resistance, adhesion to intestinal mucosa, and stress tolerance (i.e., acid/bile) should be investigated using reliable in vitro/vivo experiments [23]. Accordingly, the antibiotic resistance of L. plantarum subsp. plantarum KCCP11226 was tested. As a result, it was confirmed to have resistance to erythromycin, gentamicin, ciprofloxacin, lincomycin, tetracycline, and streptomycin, but not against ampicillin and novobiocin (Table S1). The ability to adhere to the intestinal mucosa is a prerequisite for bacterial colonization and is one of the most important properties for ideal 
A

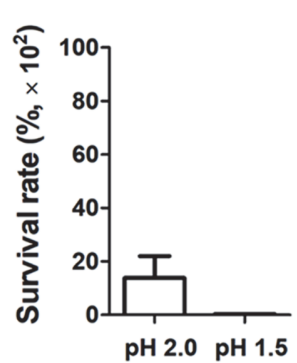

B

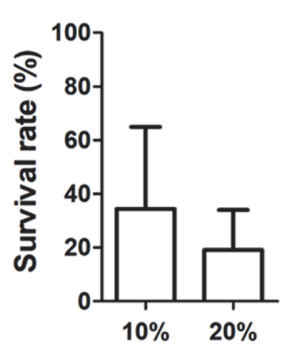

C

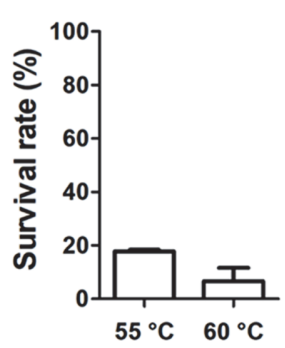

D

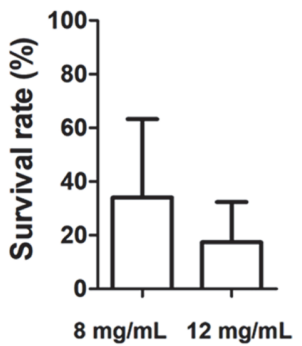

Fig. 1. Survival rate of $L$. plantarum subsp. plantarum KCCP11226 after exposure to external stress. (A) Low $\mathrm{pH},(\mathbf{B})$ bile acid, (C) high temperatures, (D) lysozyme. The bacterial cells were exposed to $30^{\circ} \mathrm{C}$ for $90 \mathrm{~min}$ (acid and bile conditions), $20 \mathrm{~min}$ (high temperature conditions), and $180 \mathrm{~min}$ (lysozyme conditions).

probiotic strains. Adherence of bacterial cells is usually correlated with cell surface hydrophobicity [24]. The cell surface hydrophobicity of strain KCCP11226 producing 4,4'-diaponeurosporene was measured and showed 66.1 $\pm 2.2 \%$ and $96.2 \pm 0.5 \%$ against xylene and toluene, respectively (Fig. S1). These values were significantly higher than those of L. rhamnosus GG as the most well-studied probiotic bacterium, which showed $56.7 \%$ and $82.8 \%$ hydrophobicity against xylene and toluene, respectively $(p<0.01)$.

In addition, the ability to survive after ingestion is an important characteristic of probiotic microorganisms because they are exposed to low $\mathrm{pH}$ and bile acids during passage through the digestive tract. As shown in Fig. 1A, strain KCCP11226, when exposed to fairly severe acid (pH 2.0 and 1.5) for 90 min, showed survival rates of $0.139 \%$ and $0.003 \%$, respectively. However, considering the initial number of cells $\left(7.3 \times 10^{7}\right.$ and $6.0 \times 10^{7} \mathrm{CFU} / \mathrm{ml}$, respectively), we confirmed that a significant number of cells still survived $\left(1.0 \times 10^{5}\right.$ and $1.8 \times 10^{3} \mathrm{CFU} / \mathrm{ml}$, respectively). The resistance of strain KCCP11226 to bile acid was tested at $10 \%$ and $20 \%$ oxgall. Considering that a typical bile acid resistance experiment was performed at less than $1 \%$ oxgall [25], the applied concentrations were very harsh conditions. However, interestingly, we confirmed that over $34.5 \pm 30.4 \%$ and $19.1 \pm 15.0 \%$ of cells can survive under the treatments of $10 \%$ and $20 \%$ oxgall, respectively (Fig. 1B). In addition, heat stress during food manufacturing and lysozyme in dairy products are important factors influencing cell death [14]; hence, the resistance of strain KCCP11226 to them was investigated. The survival rates against heat stress were $17.8 \pm 0.6 \%$ and $6.7 \pm 4.9 \%$ at $55^{\circ} \mathrm{C}$ and $60^{\circ} \mathrm{C}$, respectively (Fig. 1C). Furthermore, $34.0 \pm 29.2 \%$ and $17.4 \pm 15.0 \%$ of the initial cells survived at 8 and $12 \mathrm{mg} / \mathrm{mL}$ of lysozyme exposure, respectively (Fig. 1D). In addition to the above-mentioned external stresses, our previous study also revealed that the strain KCCP11226 showed the high survival rates $(0.79 \%$ and $0.11 \%)$ under oxidative stress after exposure to $\mathrm{H}_{2} \mathrm{O}_{2}$ at concentrations of $16 \mathrm{mM}$ and $32 \mathrm{mM}$, respectively [8].

Taken together, these results indicate that L. plantarum subsp. plantarum KCCP11226 has considerable potential as a probiotic strain because it shows survival under very harsh acid and bile conditions as well as external stress such as heat and lysozyme.

Carotenoid Production of $L$. plantarum subsp. plantarum KCCP11226 Induced by Low Temperature Stress

The time profiles of cell growth and $\mathrm{C}_{30}$ carotenoid production by strain KCCP11226 were investigated under static growth conditions at $30^{\circ} \mathrm{C}$. The cell growth and carotenoid levels were measured every $2 \mathrm{~h}$. After $12 \mathrm{~h}$ of incubation, cell growth reached the stationary phase and the time profile of $\mathrm{C}_{30}$ carotenoid production exhibited with similar trends to that of cell growth, showing the maximal carotenoid production of $0.46\left(\mathrm{~A}_{470}\right)$ after $24 \mathrm{~h}$ of cultivation (Fig. 2).

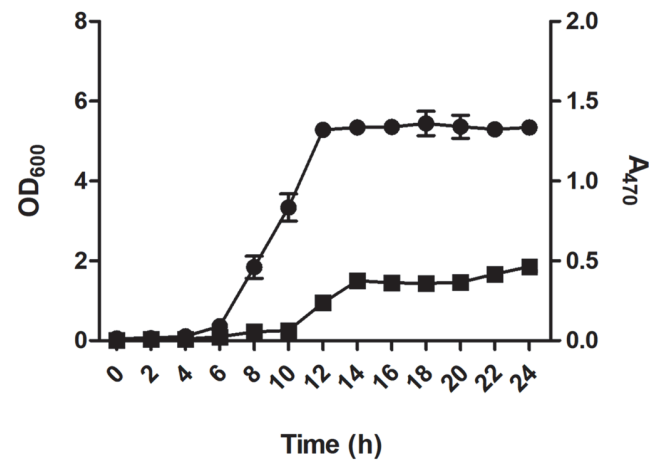

Fig. 2. Time profiles of cell growth and carotenoid production of L. plantarum subsp. plantarum KCCP11226. The bacterial cells were statically grown at $30^{\circ} \mathrm{C}$ for $24 \mathrm{~h}$. Circles and squares indicate cell growth $(600 \mathrm{~nm})$ and carotenoid production $(470 \mathrm{~nm})$, respectively. 


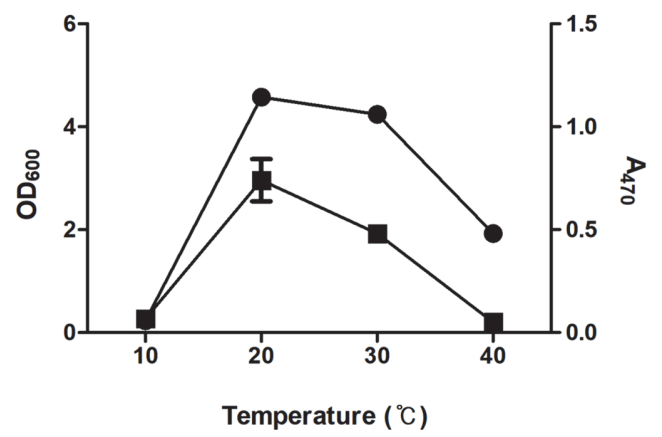

Fig. 3. Effect of cultivation temperature on cell growth and carotenoid production of $L$. plantarum subsp. plantarum KCCP11226. The bacterial cells were statically grown at various temperatures $\left(10^{\circ} \mathrm{C}, 20^{\circ} \mathrm{C}, 30^{\circ} \mathrm{C}\right.$, and $\left.40^{\circ} \mathrm{C}\right)$ for $24 \mathrm{~h}$. Circles and squares indicate cell growth $(600 \mathrm{~nm})$ and carotenoid production $(470 \mathrm{~nm})$, respectively.

The induction of carotenoid production by strain KCCP11226 was investigated through $24 \mathrm{~h}$ culture at various temperatures $\left(10^{\circ} \mathrm{C}, 20^{\circ} \mathrm{C}, 30^{\circ} \mathrm{C}\right.$, and $40^{\circ} \mathrm{C}$ ) (Fig. 3). As a result, the cells hardly grew at the low temperature of $10^{\circ} \mathrm{C}$; hence, no carotenoid was produced. In addition, the cells grew in significant amounts up to $1.93\left(\mathrm{OD}_{600}\right)$ at a relatively high temperature of $40^{\circ} \mathrm{C}$, but little carotenoid $\left(0.05\right.$ at $\left.\mathrm{A}_{470}\right)$ was produced. On the other hand, at relatively mild temperatures of $20^{\circ} \mathrm{C}$ and $30^{\circ} \mathrm{C}$, the cells grew at 4.58 and $4.24\left(\mathrm{OD}_{600}\right)$, respectively. However, there was a significant difference in carotenoid production. At $30^{\circ} \mathrm{C}, 0.48\left(\mathrm{~A}_{470}\right)$ of carotenoid was produced, but a much higher amount of $0.74 \pm 0.2\left(\mathrm{~A}_{470}\right)$ was produced at $20^{\circ} \mathrm{C}$, which is a relatively low temperature. Temperature is a significant factor affecting the carotenoid biosynthetic pathway depending on the specificity of microbial species, followed by the quantity variation of produced carotenoids [26]. Simpson et al. (1964) investigated the increase of $\beta$-carotene production from oleaginous red yeast Rhodotorula glutinis by decrease of culture temperature [27]. Another previous study also reported that the representative carotenoid produced by red yeast Phaffia rhodozyma was changed from torularhodin to astaxanthin by decrease of culture temperature from $30^{\circ} \mathrm{C}$ to $20^{\circ} \mathrm{C}$ [28].

In fact, our previous study already investigated the enhancement of $\mathrm{C}_{30}$ carotenoid production from L. plantarum subsp. plantarum KCCP11226 by employing the oxidative and salt stresses, which resulted in aerobic condition and high concentration of sodium chloride having positive effects on the increase of carotenoid production [9]. Likewise, various factors affecting carotenogenesis in microorganisms, such as light, metal ions, and chemical agents, have also been reported [29]. However, most of these studies have been limited to yeast producing $\mathrm{C}_{40}$ carotenoids [26], while carotenogenesis studies targeting lactic acid bacteria have not been actively conducted. Therefore, further studies are needed on the strategies for improving the production yield of microbial carotenoid, in particular carotenoid-biosynthesizing lactic acid bacteria as alternative sources of natural $\mathrm{C}_{30}$ carotenoids.

Antioxidant Activity of 4,4'-Diaponeurosporene Extracted from L. plantarum subsp. plantarum KCCP11226

Radical scavenging assays using DPPH and ABTS radicals are widely used to evaluate the antioxidant activity of biological samples [30]. In this study, 4,4'-diaponeurosporene extracted from strain KCCP11226 showed significantly higher DPPH free radical scavenging activity than the same concentration of butylated hydroxytoluene (BHT), which is a well-known antioxidant food additive (Fig. 4A). At $0.25,0.5$, and $1 \mathrm{mM}, 4,4^{\prime}-$ diaponeurosporene had $65.3 \pm 2.5 \%, 87.4 \pm 0.7 \%$, and $92.0 \pm 4.9 \% \mathrm{DPPH}$ radical scavenging activity, respectively, whereas BHT showed $23.1 \pm 0.4 \%, 35.7 \pm 1.3 \%$, and $53.2 \pm 1.0 \%$, respectively. In previous studies, fucoxanthin

A

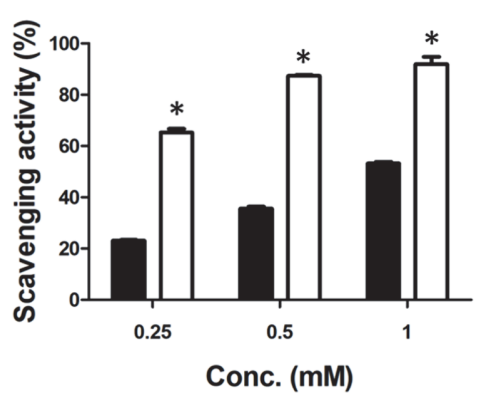

B

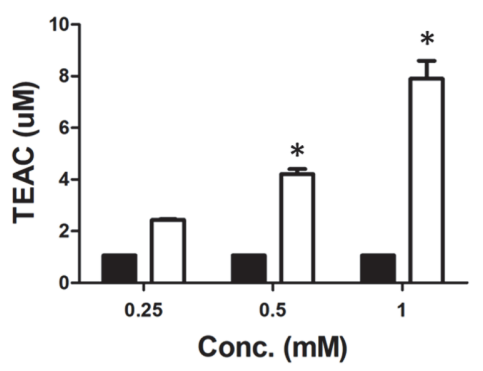

Fig. 4. Antioxidant activity of 4,4'-diaponeurosporene extracted from $L$. plantarum subsp. plantarum KCCP11226. (A) DPPH and (B) ABTS scavenging activity of the 4,4'-diaponeurosporene. Black and white bars show BHT and $4,4^{\prime}$-diaponeurosporene, respectively. The results from three independent tests are represented as means $\pm \mathrm{SD}$. Significant means were expressed after analysis of variance (ANOVA) with Tukey-Kramer multiple comparison tests $\left({ }^{*} p<0.01\right)$. 


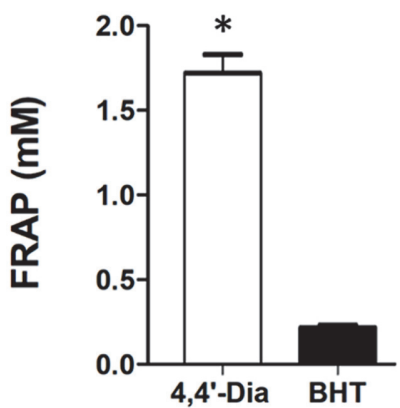

Fig. 5. FRAP values of 4,4'-diaponeurosporene extracted from L. plantarum subsp. plantarum KCCP11226. The applied concentrations are $0.25 \mathrm{mM}$ each of $4,4^{\prime}$-diaponeurosporene $\left(4,4^{\prime}\right.$-Dia) and BHT. The results from three independent tests are represented as means \pm SD. Significant means were calculated by the unpaired $t$-test with Welch's correction $\left({ }^{*} p<0.01\right)$.

showed 70\% DPPH radical scavenging activity at a concentration of $300 \mathrm{mM}$ [11]. In the case of astaxanthin and $\beta$ carotene, DPPH radical scavenging activity was shown to be $52 \%$ and $36 \%$ at $1.5 \mathrm{mM}$ concentration, respectively [31]. As a result, we confirmed that $4,4^{\prime}$-diaponeurosporene had significantly better DPPH radical scavenging activity than other carotenoids.

In addition, 4,4'-diaponeurosporene effectively scavenged ABTS radicals in a concentration-dependent manner. In the Trolox equivalent antioxidant capacity (TEAC) analysis using Trolox as a reference compound, $0.25,0.5$, and $1 \mathrm{mM}$ of $4,4^{\prime}$-diaponeurosporene showed $2.4 \pm 0.1,4.2 \pm 0.3$, and $7.9 \pm 1.2 \mu \mathrm{M}$ of TEAC value, respectively (Fig. 4B). In contrast, only $1.1 \mu \mathrm{M}$ of TEAC value was observed in all cases of the corresponding BHT concentration. Moreover, the FRAP assay was also performed because it is closely related to other antioxidant properties as an indicator of electron donating activity [32]. The effect of antioxidants on ferric reducing activity is primarily due to the size of the conjugated double bond system [33]. As a result, 4,4'-diaponeurosporene showed FRAP values of $1.7 \pm 0.1$, which was 8.0-fold higher compared to that of BHT (0.2) at the same concentration (0.25 mM) (Fig. 5).

In conclusion, L. plantarum subsp. plantarum KCCP11226, which is the main Lactobacillus species producing, 4,4'-diaponeurosporene, satisfies the conditions for use as a probiotic strain by surviving under various harsh conditions. In addition, 4,4'-diaponeurosporene, a $\mathrm{C}_{30}$ carotenoid produced by strain KCCP11226, exhibits good antioxidant activity. Therefore, strain KCCP11226 may be a useful functional antioxidant producer and a strain that can also be applied in the probiotic industry.

\section{Acknowledgments}

This work was supported by the National Research Foundation of Korea (NRF) grants funded by the Korea government (MSIT) (No. 2019R1A2C1006038 and 2019R1A2C2089870). This research was also supported by the Ottogi Ham Taiho Foundation.

\section{Conflict of Interest}

The authors have no financial conflicts of interest to declare.

\section{References}

1. Mussagy CU, Winterburn J, Santos-Ebinuma VC, Pereira JFB. 2019. Production and extraction of carotenoids produced by microorganisms. Appl. Microbiol. Biotechnol. 103: 1095-1114.

2. Sen T, Barrow CJ, Deshmukh SK. 2019. Microbial pigments in the food industry-Challenges and the way forward. Front. Nutr. 6: 7.

3. Garrido-Fernández J, Maldonado-Barragán A, Caballero-Guerrero B, Hornero-Méndez D, Ruiz-Barba JL. 2010. Carotenoid production in Lactobacillus plantarum. Int. J. Food Microbiol. 140: 34-39.

4. Siezen RJ, van Hylckama Vlieg JE. 2011. Genomic diversity and versatility of Lactobacillus plantarum, a natural metabolic engineer. Cell. Fact. 10: S3.

5. Zago M, Fornasari ME, Carminati D, Burns P, Suàrez V, Vinderola G, et al. 2011. Characterization and probiotic potential of Lactobacillus plantarum strains isolated from cheeses. Food Microbiol. 28: 1033-1040.

6. Lee PC, Schmidt-Dannert C. 2002. Metabolic engineering towards biotechnological production of carotenoids in microorganisms. Appl. Microbiol. Biotechnol. 60: 1-11.

7. Turpin W, Renaud C, Avallone S, Hammoumi A, Guyot J-P, Humblot C. 2016. PCR of crtNM combined with analytical biochemistry: An efficient way to identify carotenoid producing lactic acid bacteria. Syst. Appl. Microbiol. 39: 115-121.

8. Kim M, Seo D-H, Park Y-S, Cha I-T, Seo M-J. 2019. Isolation of Lactobacillus plantarum subsp. plantarum producing $\mathrm{C}_{30}$ carotenoid 4,4'-diaponeurosporene and the assessment of its antioxidant activity. J. Microbiol. Biotechnol. 29: 1925-1930.

9. Kim M, Jung D-H, Seo D-H, Chung W-H, Seo M-J. 2020. Genome analysis of Lactobacillus plantarum subsp. plantarum KCCP11226 reveals a well-conserved $\mathrm{C}_{30}$ carotenoid biosynthetic pathway. 3 Biotech. 10: 450 .

10. Sachindra NM, Sato E, Maeda H, Hosokawa M, Niwano Y, Kohno M, et al. 2007. Radical scavenging and singlet oxygen quenching activity of marine carotenoid fucoxanthin and its metabolites. J. Agric. Food Chem. 55: 8516-8522.

11. Zhang Y, Fang H, Xie Q, Sun J, Liu R, Hong Z, et al. 2014. Comparative evaluation of the radical-scavenging activities of fucoxanthin and its stereoisomers. Molecules 19: 2100-2113. 
12. Bergamini CM, Gambetti S, Dondi A, Cervellati C. 2004. Oxygen, reactive oxygen species and tissue damage. Curr. Pharm. Design 10: $1611-1626$.

13. Young AJ, Lowe GM. 2018. Carotenoids—antioxidant properties. Antioxidants 7: 28.

14. Hagi T, Kobayashi M, Kawamoto S, Shima J, Nomura M. 2013. Expression of novel carotenoid biosynthesis genes from Enterococcus gilvus improves the multistress tolerance of Lactococcus lactis. J. Appl. Microbiol. 114: 1763-1771.

15. Steiger S, Perez-Fons L, Fraser P, Sandmann G. 2012. Biosynthesis of a novel $\mathrm{C}_{30}$ carotenoid in Bacillus firmus isolates. J. Appl. Microbiol. 113: 888-895.

16. Young AJ, Lowe GM. 2001. Antioxidant and prooxidant properties of carotenoids. Arch. Biochem. Biophys. 385: 20-27.

17. Ekmekci H, Aslim B, Ozturk S. 2009. Characterization of vaginal lactobacilli coaggregation ability with Escherichia coli. Microbiol. Immunol. 53: 59-65.

18. Kim SH, Kim MS, Lee BY, Lee PC. 2016. Generation of structurally novel short carotenoids and study of their biological activity. Sci. Rep. 6: 21987.

19. Chae HS, Kim K-H, Kim SC, Lee PC. 2010. Strain-dependent carotenoid productions in metabolically engineered Escherichia coli. Appl. Biochem. Biotechnol. 162: 2333-2344.

20. Wieland B, Feil C, Gloria-Maercker E, Thumm G, Lechner M, Bravo J-M, et al. 1994. Genetic and biochemical analyses of the biosynthesis of the yellow carotenoid 4,4'-diaponeurosporene of Staphylococcus aureus. J. Bacteriol. 176: 7719-7726.

21. Yang J, Li Y, Zhang L, Fan M, Wei X. 2017. Response surface design for accumulation of selenium by different lactic acid bacteria. 3 Biotech. 7: 52.

22. Han Q, Kong B, Chen Q, Sun F, Zhang H. 2017. In vitro comparison of probiotic properties of lactic acid bacteria isolated from Harbin dry sausages and selected probiotics. J. Funct. Food 32: 391-400.

23. Tulumoglu S, Yuksekdag ZN, Beyatli Y, Simsek O, Cinar B, Yaşar E. 2013. Probiotic properties of lactobacilli species isolated from children's feces. Anaerobe 24: 36-42.

24. García-Cayuela T, Korany AM, Bustos I, de Cadiñanos LPG, Requena T, Peláez C, et al. 2014. Adhesion abilities of dairy Lactobacillus plantarum strains showing an aggregation phenotype. Food Res. 57: 44-50.

25. Hu P-L, Yuan Y-H, Yue T-L, Guo C-F. 2018. A new method for the in vitro determination of the bile tolerance of potentially probiotic lactobacilli. Appl. Microbiol. Biotechnol. 102: 1903-1910.

26. Frengova GI, Beshkova DM. 2009. Carotenoids from Rhodotorula and Phaffia: yeasts of biotechnological importance. J. Ind. Microbiol. Biotechnol. 36: 163-180.

27. Simpson KL, Nakayama T, Chichester C. 1964. Biosynthesis of yeast carotenoids. J. Bacteriol. 88: 1688-1694.

28. Polulyakh OV, Podoprigora OI, Eliseev SA, Ershov YV, Bykhovskii VY, Dmitrovskii AA. 1992. Biosynthesis of torulene and torularhodin in the yeast Phaffia rhodozyma. Appl. Biochem. Microbiol. 27: 541-545.

29. Bhosale P. 2004. Environmental and cultural stimulants in the production of carotenoids from microorganisms. Appl. Microbial. Biotechnol. 63: 351-361.

30. Roginsky V, Lissi EA. 2005. Review of methods to determine chain-breaking antioxidant activity in food. Food Chem. 92: 235-254.

31. Méndez-Robles MD, Permady HH, Jaramillo-Flores ME, Lugo-Cervantes EC, Cardador-Martínez A, Canales-Aguirre AA, et al. 2006. C-26 and C-30 Apocarotenoids from seeds of Ditaxis heterantha with antioxidant activity and protection against DNA oxidative damage. J. Nat. Prod. 69: 1140-1144.

32. Hinneburg I, Dorman HD, Hiltunen R. 2006. Antioxidant activities of extracts from selected culinary herbs and spices. Food Chem. 97: 122-129.

33. Müller L, Fröhlich K, Böhm V. 2011. Comparative antioxidant activities of carotenoids measured by ferric reducing antioxidant power (FRAP), ABTS bleaching assay (aTEAC), DPPH assay and peroxyl radical scavenging assay. Food Chem. 129: 139-148. 